\title{
Reporting and Interpreting Intentions in Defamation Law
}

\author{
Fabrizio Macagno
}

The relationship between quoting and indirect reporting another's words is an issue that connects the field of pragmatics to the studies in the areas of rhetoric, argumentation, and law. There is nothing more effective for establishing someone's commitments than referring to his own words (Boller 1967). However, for dialectical or rhetorical purposes, a quote can be distorted, or reported incorrectly (Walton and Macagno 2011). Commitments to positions that are scandalous or hard to defend can be attributed to an individual in order to arouse attention, discredit him, or attack him. Clearly, when words become directly connected with reputation or courtroom battles, the problem of establishing what a quote means exceeds the boundaries of pragmatics and rhetoric and becomes a legal issue. Quotes or misquotes become relevant in law when they are used for specific argumentative purposes, as instruments of defamation or powerful tools for attacking the opponent's case or defending against accusations. However, such argumentative uses presuppose a fundamental interpretative step. In these cases, a quote is not a mere repetition of a portion of another's text or speech; it is the use of another's utterance to support the speaker's viewpoint. For this reason, every quote used argumentatively is the outcome of an interpretative process. A reporter can report directly or indirectly a public figure's words to accuse, criticize, or negatively evaluate him or his behavior explicitly or implicitly, or to trigger a specific reaction in the audience. When a defamatory quote is brought before the court, its meaning is interpreted and explicated or reported to support the accusation. Similarly, the same quote needs to go through the same interpretative process to rebut the charges. The fundamental problem is to describe and provide rules and mechanisms governing the

\footnotetext{
F. Macagno $(\triangle)$

ArgLab, IFILNOVA, Faculdade de Ciências Sociais e Humanas, Universidade Nova de Lisboa, Av. de Berna 26C, Lisbon 1069-061, Portugal

e-mail: fabriziomacagno@hotmail.com
}

A. Capone et al. (eds.), Indirect Reports and Pragmatics, Perspectives

in Pragmatics, Philosophy \& Psychology 5, DOI 10.1007/978-3-319-21395-8_28 
expression of the content of an utterance at various levels, from the propositional to the perlocutionary one (Solan and Tiersma 2005: 181-183).

In the United States, in defamation law quotation and interpretation are strictly interrelated. At common law, under the doctrine of neutral report, fair and accurate indirect reports are treated like literal quotes and protected against liability when they "accurately convey" the speaker's communicative intention (Edwards v. National Audubon Society Inc., 556 F. 2d 113, at 120, 1977; Milkovich v. Lorain Journal Co. 497 U.S. 1, 1990). Quotations, paraphrases and indirect reports fall under the same problem of interpreting what the speaker intended to communicate. The interpretative passage from a quote to an indirect report, corresponding to making explicit the intended meaning, becomes thus crucial. The legal rules of interpretation are aimed at regulating specific strategies of misquotation, in which an individual's words are not necessarily distorted or misrepresented, but simply reported or paraphrased out of their co-text or communicative context. The principles of legal interpretation set out in Masson and other leading cases and the application thereof are extremely important for pragmatics and argumentation theory. To what extent is it possible to wrench a quote out of its context? How to represent and establish the relationship between an utterance, and its dialogical setting and co-text?

The various strategies used to misrepresent communicative intentions will be analyzed and used to underline the various dimensions of the contextual reconstruction of the meaning of an utterance. In particular, the issue of interpreting and distorting communicative intentions will be addressed from an argumentative and pragmatic perspective. Dialogical intentions will be represented as higher predicates, called dialogue-game predicates, which establish the role of the various speech acts performed by the interlocutors. On this view, the effectiveness of the strategies of misquotation (or misrepresentation of intentions) will be shown to be related with the conflict between presumptive interpretation and the nonpresumptive one, which is drawn from an analysis of the relationship between an utterance and the higher predicate governing it.

\section{Reporting Intentions}

The passage from a quotation to an indirect report constitutes an extremely important issue for the semantic-pragmatic distinction, and the problem of semantic underdeterminacy and the reconstruction of what is said. Recanati (2004) underscored that what is said cannot be separated from the contextual information. On the contrary, "saying" is seen as a matter of intention recognition, in which primary pragmatic processes (as distinct from the ones leading to implicatures) intervene to determine the explicit, accessible meaning. In order to reconstruct the propositional form of a sentence, its logical form needs to be saturated, i.e., its indexicals need to be assigned semantic values. However, in addition to this linguistic process, other pragmatic ones intervene to determine the speaker's intention: free-enrichment 


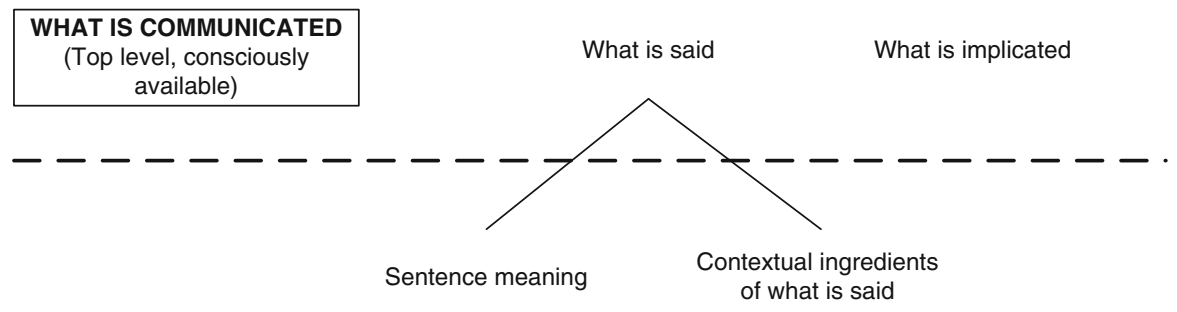

\section{SUB-PERSONAL LEVEL}

Fig. 1 What is said and what is communicated

(including specifization of meaning), loosening (or widening of the conditions of application of a predicate, Carston 1997), and semantic transfer, generating ad-hoc concepts starting from the lexical concepts. In this sense, what is said becomes a component of what is communicated, together with what is implicated (Recanati 2004: 50) (Fig. 1).

What is said, or explicit meaning, needs to be determined based on the intuitions of the interlocutors in a normal conversational setting, i.e., as the outcome of an inferential process of reconstruction from textual and pragmatic indicators (Carston 2002). Such a process is usually treated in pragmatics under the label of explicature, i.e., an assumption by an utterance $U$ that is a development of a logical form encoded by $U$ (Sperber and Wilson 1986: 54). Explicatures fix and represent the speaker's communicative intention by reconstructing both what the speaker intends to communicate, and the illocutionary force of the utterance expressing it (Capone 2009: 73). In this sense, a truth-evaluable proposition results from combining the linguistic materials of the sentence with the pragmatic elements of the explicature, adding to the former the pragmatic assumptions drawn from the context (BurtonRoberts 2006).

In the passage from a quotation to its interpretation in an indirect report, the representation of the possible implications thereof becomes extremely problematic. The distinction between what is said and what is implicated cannot be traced at the explicit vs. implicit level, but at the level of commitments, focusing on the problem of the possibility of retracting them. The assertion of a sentence $p$, with the intention to "assert or convey $p$ involves doing so with the intention of committing oneself to $p$ " (Soames 2002: 73). While explicit meaning is reconstructed by taking into account the individual communicative intention, the implicated meaning can be more problematic. The commitment to implicit meaning is the result of a further process of reasoning, in which the reconstructed explicit meaning is processed by taking into account the conversational presumptions (Sperber and Wilson 1986: 162; Lascarides and Asher 1991: 57; Rescher 1977: 26) and the purpose of a communicative move within a dialogue game, namely the joint communicative purpose (Rocci 2005: 103; Walton and Macagno 2007; Macagno 2008). In this latter 
case, the explicitly intended meaning may be claimed to conflict with the implicated one, so that the commitment to the latter is retracted. A leading case is Bronston $v$. U.S. (409 U.S. 359, 1973), in which, during the cross-examination phase the lawyer asked the witness a question, which was answered in a pragmatically ambiguous way:

Case 1: Interpretation and dialogue games - Implicatures

"Q. Do you have any bank accounts in Swiss banks, Mr. Bronston?"

"A. No, sir."

"Q. Have you ever?"

"A. The company had an account there for about six months, in Zurich."

From a communicative point of view, the witness is engaged in a dialogue game in which he has to answer the questions made by the examiner. In this case, the question allows for the possibility of a positive or negative reply, or a refusal to answer (which needs to be motivated) (Ducrot 1972: 20; Ducrot and Anscombre 1986: 88). The witness, in order to take part in the dialogue game, needs to comply with the rules of the joint dialogical game, and provide an answer falling in the possible options that the question opens up. Since the explicit meaning is irrelevant to the purpose of the joint dialogical activity, the examiner reconstructed the individual communicative intention in coherence with the joint one that he presumed to be in contradiction with the dialogical context. The implicature, namely that the witness never had a bank account in a Swiss bank, was the result of a wrongful reconstruction of the dialogue game (interpreted as an ordinary conversation and not as a cross-examination). In this case, the lawyer held the interlocutor committed to a proposition that the latter could retract. The witness did have a bank account in a Swiss bank, but he never said so explicitly, and was found to have testified truthfully.

The distinction between explicature and implicature, and the crucial problem of representing the speaker's communicative intention lies beneath the mechanism of indirect reports and the paraphrases of what is said. Indirect reports may have the practical purpose of eliminating opacity by providing the implicit assumptions needed to reconstruct the explicit meaning of an utterance (Wieland 2013). However, the reconstruction of the explicit meaning of quotations may lead to altering the possible implicit meaning that an interlocutor may draw from it (Capone 2013: 170). A mere paraphrase of a quote, consisting in the free replacement of co-extensive terms, can lead to, or make explicit, unwanted inferences, or cancel wanted ones, leading to a misrepresentation of the communicative intention (Capone 2010). The subtle line between explicature and manipulation in the interpretation of quotes goes back to the crucial issue of representing the intended communicative intention. If an indirect report risks manipulating the speaker's intention by reporting a different intention, a quote wrenched from its co-text and context can be explicated by attributing to it a meaning not intended by the speaker.

The problem of defining, representing, and reconstructing communicative intentions becomes fundamental for establishing when a quote has been correctly explicated or instead altered or manipulated. In particular, in defamation law these problems become extremely relevant, as they are directly linked with the 
notions of falsity and liability. To what extent is it possible to explicate (or rather indirectly report) the meaning of a quotation without altering the speaker's intended commitments and his intentions? When does a literal quote become a misquotation, and when does a quote wrenched from its context lead to explicatures different from the intended ones (Capone 2013: 166)? The criteria that are used at common law in the United States can point out some fundamental aspects of interpretation.

\section{Quotations and Meaning Reconstruction in Law}

The line between explicating and altering the content of a quotation was traced in law by the leading federal case Masson v. New Yorker Magazine, Inc. (501 U.S. 496, 1991). The petitioner, the Projects Director of the Sigmund Freud Archives (Masson), granted a reporter of the New Yorker Magazine a series of interviews in which he narrated his experience at the archives. Based on these interviews, the reporter published an article in which he used quotation marks to attribute to him comments that, however, Masson had never made. Masson pressed charges and sued the magazine for defamation. The court had to establish to what extent a paraphrase of the speaker's words can be considered as deliberate falsification.

The first crucial issue was to take into account the relationship between the context and the quote. While in a legal discussion quotations are expected and required to report the speaker's actual words, in an ordinary context, such as a newspaper article, quotations may not "convey that the speaker actually said or wrote the quoted material” (Masson v. New Yorker Magazine, 501 U.S. 496, 1991), as writers "often use quotation marks, yet no reasonable reader would assume that such punctuation automatically implies the truth of the quoted material" (Baker v. Los Angeles Examiner, 42 Cal. 3d at 263, 1986). In journalistic writing if no clues or explicit declarations are provided, the reader is led to believing that the quotations are being used as a rhetorical device or to paraphrase the speaker's actual statements. However, verbatim repetition needs to be distinguished from rational interpretation: "the quotation marks indicate that the author is not interpreting the speaker's ambiguous statement, but is attempting to convey what the speaker said" (501 U.S. at 519). When quoting, a reporter is presumed to convey the communicative intention of the speaker, without altering the intended meaning. By focusing on the "substantial truth" of the quote, the Court overlooked the distinction between indirect and direct quote, basically equating a verbatim repetition of someone's words with an explicated quote (namely containing all the necessary explicatures) and an indirect report (De Grazia 1995: 282-283).

By considering the explicature of a speaker's statements as equivalent to a quotation, the court incurred a further problem, i.e., determining the boundaries of explicatures. The legal rationale used to draw these distinctions was the concept of "material alteration." As the Supreme Court maintained, "[ ... ] when dealing with material that is portrayed as a quotation, we are to compare the quotation as published with the words the speaker actually said" (501 U.S. at 502); "<where> 
the published quotation contains a material alteration of the meaning conveyed by the speaker, the published quotation is false" (Id. at 517). Such an intended meaning includes two fundamental dimensions in addition to the factual content: the illocutionary purpose and the possible inferences that can be drawn from an assertion.

The problem of establishing the illocutionary force of an utterance was dealt with in another important federal case, Milkovich v. Lorain Journal Co., where the issue of determining whether a statement was defamatory or not depended on its pragmatic purpose, namely to convey an opinion or a statement of fact. In the aforementioned case, the two legally relevant pragmatic purposes are distinguished according to three standards (497 U.S. 17, 1990):

1. Is the language loose, figurative, or hyperbolic, which would negate the impression that the speaker was seriously maintaining the truth of the underlying facts?

2. Does the general tenor of the article negate the impression that the speaker was seriously maintaining the truth of the underlying fact?

3. Is the connotation sufficiently factual to be susceptible of being proved true or false?

According to these standards, the reporter needs to convey the intended purpose of the utterance: he needs to establish whether the speaker intended to describe a state of affairs or to express a personal opinion on it. Whereas the pragmatic intention of expressing an opinion is protected by the First Amendment (freedom of speech and press), the one of uttering a statement of fact is not, and is actionable under the incremental harm doctrine. The reconstruction of the communicative intention is closely related with the retrieval and attribution of the possible inferences that can be drawn from an utterance and the reporting thereof. What are the boundaries of attributing intentions? The legal answer lies in the concept of commitment.

The first limit of attributing intention consists in the pragmatic ambiguity of an utterance. The quoter or the reporter cannot attribute to the speaker commitments that were merely suggested and covered by ambiguity. The speaker may have wanted to let the interlocutor draw possible inferences, without committing to them. Such a potential pragmatic ambiguity cannot be explicated without altering materially the speaker's statement, modifying his commitments (see Capone 2003). A leading example is the following misquotation in Masson v. New Yorker Magazine (501 U.S. at 504). The reporter quoted Masson as stating (emphasis added):

Case 2: Misquotation: "Place of sex, women, fun"

It was a beautiful house, but it was dark and somber and dead. Nothing ever went on there. I was the only person who ever came. I would have renovated it, opened it up, brought it to life. Maresfield Gardens would have been a center of scholarship, but it would also have been a place of sex, women, fun. It would have been like the change in The Wizard of Oz, from black-and-white into color.

Masson merely stated that "Freud's library alone is priceless," while in other passages he claimed that he and another analyst planned to have great parties at the Freud house and (in a context that may not even refer to Freud house activities) to 
"pass women on to each other" (501 U.S. at 524, 525). Even if the reporter provided a possible interpretation of the speaker's words, such an interpretation was based on possible inferences and disambiguation. For this reason, the quote was considered by the Supreme Court as substantially different, reversing the opinion of the Court of Appeals.

The second limit concerns the possible inferences that a reasonable reader can draw from an utterance. The quoting or reporting party cannot attribute to the speaker more commitments than the ones intended. Not only does a material alteration consist in modifying the factual content of an assertion, but also the possible inferences, especially the evaluative ones. Even if a fabricated quotation or an indirect report asserts something that is true as a factual matter, the quote or the report may nonetheless "result in injury to reputation because the manner of expression or even the fact that the statement was made indicates a negative personal trait or an attitude the speaker does not hold" (Id. at 511). Using the terminology of Stevenson $(1937,1944)$, different statements may convey the same "descriptive" meaning, but different "emotive" one, i.e., they may trigger quite different inferences (Macagno and Walton 2014). A quote from the case Masson v. New Yorker Magazine was based on the different inferences, i.e., the intended and optimal inherent perlocutionary effects (Van Eemeren and Grootendorst 1984: 2528) of the petitioner's and the reporter's statements. Masson was quoted as stating in discussing an affair with a graduate student (501 U.S. at 503, emphasis added):

Case 3: Misquotation: "Intellectual gigolo"

Eissler and Anna Freud told me that they like me well enough "in my own room." They loved to hear from me what creeps and dolts analysts are. I was like an intellectual gigolo - you get your pleasure from him, but you don't take him out in public.

However, the actual statement was different (501 U.S. at 503, emphasis added):

Case 3: "Intellectual gigolo" - Actual quote

[Eissler and Anna Freud] felt, in a sense, I [Masson] was a private asset but a public liability. They like me when I was alone in their living room, and I could talk and chat and tell them the truth about things and they would tell me. But that I was, in a sense, much too junior within the hierarchy of analysis, for these important training analysts to be caught dead with me.

The quoted statement merely reported Kurt Eissler's and Anna Freud's opinions about petitioner, expressing no different factual contents or "descriptive meaning." For this reason, the district court claimed that "the descriptive term 'intellectual gigolo,' as used in this context, simply means that Masson's views were privately entertaining, but publicly embarrassing to Freud and Eissler." The Supreme Court took into account also the "emotive meaning" of the reported quote, expressing a value judgment that was absent in Masson's statement. In this sense, the New Yorker Magazine reported falsely an assessment, and for this reason the judgment was reversed, as the quoted and the original statement were materially different (501 U.S. 521): "fairly read, intellectual gigolo suggests someone who forsakes intellectual integrity in exchange for pecuniary or other gain." Even though the two statements conveyed the same descriptive meaning, the inferences and the value 
judgment the quotation elicited were different, and this modification was held to be a material change, as it affected the evaluation of the speaker.

These rules of interpretation lead to a closely related issue, i.e., the contextual interpretation of an utterance, or rather the conflict between the effects the speaker intended his utterance to carry out and the ones that the utterance resulted in. At common law, the answer was found in the relationship between the quoted or reported speech, the reported context, and the average reader.

\section{The Context, the Speaker, and the Limits of Interpreting Intentions}

The aforementioned general federal rules establish how a linguistic "fact" (an utterance) cannot be modified by reporting it directly or indirectly, through a personal interpretation of the speaker's intention. Both the "descriptive" and the "emotive" meaning of an utterance need to be quoted or reported correctly, and the possible pragmatic ambiguities cannot be solved. In this way, the explicit intention of the speaker, i.e., his intended commitments, can be made explicit without possible alterations. However, what happens when the speaker claims to have intended his utterance to result in a specific effect (or inferences), which was not recognized? What happens when the recipient of an utterance interprets it contextually as carrying out effects that the speaker denies? The analysis of the context may risk blurring the line between what is said and why it has been said.

The relationship between a quote and its context is of fundamental importance in order to determine the defamatory, and thus communicative, intended effects of an utterance. A clear case in which the investigation of the context becomes relevant is Webster v. Wilkins (217 Ga. App. 194, 1995). A newspaper article quoted a professional basketball player Jacques Dominique Wilkins saying of his previous partner (Webster): "[Webster] gives women in general a bad name . . . I probably shouldn't say this, but I want to take that kid from her. She's unfit to have a kid." Based on this quote, Webster sued Wilkins and Cox for defamation, claiming that Wilkins' statement "unfit to have a kid" cannot be considered as an opinion, but a statement of fact. The plaintiff claimed that such an assertion is capable of being proved to be false because fitness as a parent could be determined by a court of law pursuant to criteria set forth by law. In this sense, Wilkins interpreted his own statement as, " $<$ I said that $><$ Webster $>$ is unfit $<$ from a legal point of view $>$ to have a child <as she does not meet the legal requirements for being considered to be fit to be a parent $>$." The court, however, analyzed the statement in its original context, and calculated the possible effects that it could have meant to have on the average reader (217 Ga. App. 194, 195):

Case 4: Misquotation - "Unfit to have a kid"

Having reviewed Wilkins' statement in the context of the entire article, we cannot make this assumption. It is apparent from the context of the article that Wilkins did not use the phrase "unfit to have a kid" in its legal sense or as a legal conclusion, but used it only to 
express his subjective opinion criticizing Webster's parental abilities. More importantly, the average reader would not have construed Wilkins' statement to be his legal conclusion that pursuant to OCGA $\S \S 19-7-1$ and 19-7-4 Webster is an unfit parent. [... ] Webster's reading of Wilkins' words is such a strained construction because the average reader, construing the statement in the context of the entire article, would have taken the statement for what it was, a subjective, hyperbolic opinion that cannot be proved to be true or false and that concerns a matter on which reasonable people might differ; i.e., Webster's parental capabilities.

The statement can be pragmatically disambiguated only by resorting to the original context in which it was uttered (a conversation between a basketball player and a reporter) and the possible interpretation thereof by an average reader (i.e., a person interested in gossip and sport news). If the context is taken into account, and the "emotive" meaning of a quote needs to be reported correctly or duly explicated, a further problem arises. What happens when a statement is quoted and explicated by taking into account the reasonable inferences that can be drawn from it in the specific context in which it was uttered? This problem is directly connected with the issue of determining the distinction between the explicit and the implicit intentions (Raudenbush 1991: 1491).

In law, the reporting of a speaker's communicative intention needs to preserve the possible inferences, that is, "the natural and probable effect upon the mind of the average reader" (MacLeod v. Tribune Publishing Co., 343 P.2d 36, 546, Cal. 1959). The explicature of a statement, in this sense, cannot go beyond the meaning that can be reasonably attributed by an ordinary reader or hearer, and cannot support the slanderous nature of a statement by resorting to the reasons underlying the judgment expressed by the speaker. A clear case is the interpretation of "disgrace" in Bauer v. Murphy (530 N.W.2d 1, Wis. Ct. App. 1995), where the plaintiff brought a defamation claim against the defendant based on an discussion between the two, in which Murphy called Bauer "a disgrace" to the team and the university, referring to an alleged relationship between Bauer and the team coach. The defamation claim was based on the interpretation of Murphy's quote (at 529):

\title{
Case 5: Interpretation of "disgrace"
}

\begin{abstract}
Bauer next argues that Murphy's remark is slanderous per se because, when taken in the context of the discussion at the meeting, it "declare [d] that [Bauer] was guilty of disgraceful [sexual] acts with Coach Peckham," [...]. Bauer has not persuaded us that Murphy's "disgrace" remark imputed "serious sexual misconduct" to her within the meaning of the Restatement rule. Nor do we see that the context in which Murphy's remark was made adds a sexual misconduct gloss to her words. [...] As the court also recognized, however, [to be called "a disgrace"] is "equally discreditable as applied to all persons," id., and we believe in this case that the word does not reasonably carry with it an assertion of "unchastity" or sexual misconduct, whether taken in isolation or in the context in which the remark was made.
\end{abstract}

The indirect report (or interpretation) of the allegedly defamatory statement in this case repeats the quoted material and the context verbatim, making explicit the intentions of the speaker underlying the utterance. However, such an indirect report goes beyond the speaker's intentions, as it is not possible to attribute to the speaker commitments that he did not want to hold. For this reason, the classificatory 
arguments that presumptively led Murphy to classifying Bauer as a "disgrace" cannot be reconstructed as an integral part of the explicit meaning. The explicature, and the speaker's intention, needs to be reconstructed according to what the uttered statement is intended to bring about on the communicative setting (in this case to attack directly and generally the interlocutor, leaving up to the hearers the retrieval of the reasons that led to such a discreditable classification).

In law the boundary between direct, verbatim quotations and paraphrases is blurred, and depending on the context it is possible to replace the exact quote with a report of the intended meaning of the speaker. Such an explicature of what the speaker said, however, needs to comply with clear contextual limits. A statement shall be interpreted according to what an average reader could understand from the utterance thereof in the specific context. In this sense, the speaker and the hearer are not privileged parties, but count only inasmuch as they represent the ordinary recipient of the message. For this reason, the speaker or the hearer cannot use the context to retrieve more or less commitments than the ones that an average reader would draw from the utterance. The interpreter of the intended meaning cannot "hunt for a strained construction in order to hold the words used as being defamatory" (Webster v. Wilkins, 217 Ga. App. 194, 195, 1995). The presumable or the possible speaker's communicative intention, not emerging from what he said, needs to be left out.

\section{Ambiguity and Its Argumentative Uses}

The strategic interpretation of a quote and the misrepresentation of the speaker's intentions in an indirect report are interrelated with the problems of ambiguity and its argumentative uses. Walton (1996: 262) distinguishes between three principal categories of ambiguity (Van Laar 2003): potential, actual, and imaginary ambiguity. Potential ambiguity concerns the logical form of a proposition, which results from a syntactic, inflective, or lexical ambiguity. Syntactic ambiguity arises from the possible ambiguity in the construction of the sentence, such as in the following case (adapted from Walton 1996: 113):

I hope that you the enemy will slay.

This sentence can be interpreted or reported in two different ways, as "He hopes that you will slay the enemy" and "He hopes that the enemy will slay you." Inflective ambiguity can be considered as a kind of lexical ambiguity, based on two terms that are homographs but not homophones, such as in the following case:

I resent that letter.

The sentence can be interpreted as "He said that he sent the letter again" or as "He said that he has a feeling of resentment towards the letter." The last type of potential ambiguity derives from the lexical ambiguity of a word (Engel 1980: 14), which has 
been considered since Aristotle as the classical source of the fallacy of equivocation (Sophistical Refutations 165b29-30):

Those who know grasp things; for it is those who know their letters who grasp what is dictated to them. For to grasp is homonymous; it is to understand by the use of knowledge, and also to acquire knowledge.

This type of ambiguity is related to the possible different definitions of a term, which can both occur in the same sentence.

Unlikely potential ambiguity, actual ambiguity and imaginary ambiguity concern the interpretation of a sentence in an utterance, i.e., a type of ambiguity that is pragmatic in nature (Jaszczolt 1999; Capone 2011). Actual ambiguity is generated by different contextual interpretations of the referents of indexical expressions. Aristotle analyzed the following case of ambiguity used in arguments as a source of equivocation (Sophistical Refutations, 166a1-5):

'The same man is both seated and standing and he is both sick and in health: for it is he who stood up who is standing, and he who is recovering who is in health: but it is the seated man who stood up, and the sick man who was recovering'. For 'The sick man does so and so', or 'has so and so done to him' is not single in meaning: sometimes it means 'the man who is sick or is seated now', sometimes 'the man who was sick formerly.'

Imaginary ambiguity can be distinguished in illocutionary and perlocutionary ambiguity, depending on the type of act that is subject to distinct interpretations. Illocutionary ambiguity arises when an utterance can be interpreted as instantiating two different possible speech acts (Walton 2006: 289), such as in the following case (Solan and Tiersma 2005: 184-185):

Putnam: Do you have a suggestion for me?

Crandall: Yes. I have a suggestion for you. Raise your goddamn fares twenty percent.

I'll raise mine the next morning.

The interlocutors in this conversation are the presidents of two American airline companies, and are discussing about the possibility of monopolizing the airline business in the Dallas-Fort Worth area. However, what is Crandall saying? Is Crandall requesting Putnam to violate the antitrust laws setting prices? Or is this utterance a simple suggestion, which would not be a criminal offence? In this case, Crandall wants to say that he wants Putnam to raise the prices, in order to obtain a benefit. For this reason, this speech act labeled as a "suggestion" is in fact a request (Solan and Tiersma 2005: 185).

A speech act can be also ambiguous at a perlocutionary level, when the inherent effect (distinct from the consecutive one, corresponding to the optimal effect of the act) of the illocutionary act on the interlocutor can be misinterpreted. For example the following assertion (Blair Edlow 1977: 11) can be used to elicit different types of responses:

I am in pain

This utterance is illocutionary unambiguous, but at a perlocutionary level it can be interpreted as aimed at arising empathy, informing the interlocutor (He said that he 
feels pain), or requesting help (He said that he is in trouble and wants help). The different types of ambiguity can be summarized as follows:

\begin{tabular}{l|l|l|l}
\hline Propositional ambiguity (potential ambiguity) \\
\hline Lexical & Syntactic & Intonational \\
\hline Homographs & Different definitions & $\begin{array}{l}\text { Different syntactic } \\
\text { construction }\end{array}$ & $\begin{array}{l}\text { Different deep structures } \\
\text { manifested by different } \\
\text { intonations }\end{array}$ \\
\hline Pragmatic ambiguity & \multicolumn{2}{|l}{} \\
\hline Actual ambiguity & Imaginary ambiguity & \\
\hline Propositional & Illocutionary & Perlocutionary & \\
\hline
\end{tabular}

The different types of ambiguity correspond to various types of equivocation (Walton 1996, 2000; Copi and Cohen 1990: 115). From an argumentative point of view, ambiguity can be a powerful instrument when the speaker through it can alter the interlocutor's commitments (Walton and Macagno 2010, 2011). The speaker can exploit the possible interpretation of a proposition according to two distinct logical forms (resulting in the so-called quaternion terminorum), or take advantage of the possibility of interpreting in various ways the interlocutor's utterance. However, there is a clear difference between exploiting argumentatively an already existing ambiguity of a proposition, and introducing ambiguity. In this latter case, the speaker chooses to act non-cooperatively or uncooperatively (Macagno and Damele 2013; Paglieri 2007; Oswald and Lewinski 2013) in order to alter a viewpoint for dialectical purposes. The speaker can interpret or report the interlocutor's utterance in a distorted way in order to attack him or defeat his standpoint, or to provide a reading of his own utterance that can be used for defending himself or countering the interlocutor's attacks. Misrepresentation of intentions is an instrument for introducing pragmatic ambiguity by altering the context or the co-text in which the quote occurs, or by reporting indirectly an altered communicative intention. In the section below, the various types of pragmatic ambiguity will be analyzed as different types of strategies of meaning misrepresentation in law, used for both attacking and defensive purposes.

\section{Strategies for Altering and Reporting Intentions}

In defamation law, the subtlest strategies of misrepresenting the speaker's intentions concern the boundaries between interpretation and explicit meaning, i.e., the limits of explicatures. In particular, the goal of the author of a misquotation is to increase the burden of the interlocutor (the potential plaintiff) of proving that the original statement had a different meaning. While ambiguity at a propositional level can be easily assessed by looking at the propositional form of the quoted material, pragmatic ambiguity can be more complex to analyze, as the whole co-text, context, 
and the dialogical setting need to be taken into account. As set out in Ollman v. Evans (242 U. S. App. D. C. 301, 1984), other factors shall be considered for the interpretation of a statement, in addition to the specific language used: the general context of the statement, and the broader context in which the statement appeared. Moreover, the possibility of proving the "material" or "substantial" change (see Kaltenbach 1992: 775) of the meaning of an utterance is directly linked with the issue of actual malice and liability in case of defense against possible lawsuits. Only reckless disregard for truth or falsity can prove malice, while a defendant cannot be condemned for minor inaccuracies.

By exploiting pragmatic ambiguity, a reporter can make more complex the task of showing falsity, as a statement pragmatically misquoted or misreported can be shown to be pragmatically ambiguous, or at least potentially interpretable in different ways. The same tactic can be used by the party acting as a plaintiff. By wrenching an apparently defamatory quote from its context and omitting the dialogical setting, the plaintiff can establish a prima-facie case for defamation, shifting the burden of disproving the alleged intention onto the defendant. The strategies used for pragmatically misrepresenting an utterance can be divided in three types, which rely respectively on the propositional, the illocutionary, and the perlocutionary ambiguity of an utterance.

\subsection{Propositional Pragmatic Ambiguity}

A clear case of propositional pragmatic ambiguity is Price v. Stossel (620 F.3d 992, 2010). The plaintiff, Dr. Frederick Price, an evangelic minister, was quoted in a clip broadcasted by the American Broadcasting Companies as having claimed the following during a sermon on the issue of lack of faith:

Case 6: Misquotation and indexicals - Interpreting "I"

I live in a 25 -room mansion. I have my own $\$ 6$ million yacht. I have my own private jet, and I have my own helicopter, and I have seven luxury automobiles.

$\mathrm{ABC}$ used this quote in a program on the financial openness of Christian groups, criticizing them for not revealing how they spent donations. The problem with this quote is twofold. On the one hand, it reports true facts, as Price's wealth was in fact substantial. On the other hand, the quote, taken out of context, suggested that Price was boasting about his own wealth, while in the original sermon Price was telling a parable, "speaking from the perspective of a hypothetical person who, though wealthy, was spiritually unfulfilled" (Price v. Stossel, 620 F.3d 992. 2010). The problem of falsity becomes in this case complex to assess, and the district court dismissed it, considering the truth of the facts reported (620 F.3d 992, 12701) and that the quote was in fact exact. The court of appeals, however, followed the rule set out in Masson, claiming that falsity needs to be assessed by considering the correspondence between the quote and the original statement. The ABC provided an accurate quote, but out of context, and "an exact quotation out of context can 
distort meaning, although the speaker did use each reported word" (Masson $v$. New Yorker Magazine, Inc., 501 U.S. at 515). The logical form of the statement is not ambiguous, but by not providing the needed explicature and by wrenching the quote from its context, the reporter exploited the presumptive interpretation of its propositional content (Bezuidenhout 1997; Jaszczolt 1999; Capone 2011). This utterance, when transferred to an indirect report (i.e., interpreted) or integrated through the needed explicatures, is reconstructed presumptively by attributing to the pronoun "I" the most common reference, i.e., the speaker ("Price said that he lives in..."). By omitting the more specific context, in which "I" is interpreted attributively as referring to a hypothetical person ("Price said that a person living in ..."), the reporter reported the utterance as claiming that Price was boasting about his wealth. As the Court of Appeals found, considering the purpose of the statement and the pragmatic interpretation thereof, Price could prove actual malice.

Propositional pragmatic ambiguity can be used in the journalistic style to attract attention in the headline, providing a pragmatically ambiguous statement that can be presumptively reconstructed in a fashion that is later corrected by the rest of the article. However, the boundary between falsity and strategic ambiguity is sometimes very thin, especially when the reputation of a public figure is at stake, and the potentially defamatory words are attributed to someone else than the reporter. To what extent is it possible to suggest a false piece of news that can catch a reader's interest? A famous case was debated during the course of the criminal trial of O.J. Simpson, concerning Mr. "Kato" Kaelin, the houseguest at Simpson's estate. The National Examiner, a weekly newspaper published by Globe Communications Corporation, featured the following headline on its cover (Kaelin v. Globe Communications Corp., 162 F.3 d 1036, 9th Cir., 1998):

Case 7: Misquotation and indexicals - Interpreting "it"

COPS THINK KATO DID IT!

he fears they want him for perjury, say pals.

This statement is pragmatically ambiguous, as the indirect reports of the police's and the friends' beliefs are apparently not connected (Siegel 2014: 79-80). For this reason the pronoun "it" could refer to the murders that O.J. Simpson was accused of, or the crime of perjury mentioned in the line below (162 F.3d 1036):

The first-“COPS THINK KATO DID IT!"-states what the cops supposedly think. The second, "he fears they want him for perjury, say pals"-is what Kato's pals supposedly said. These two sentences express two different thoughts and are not mutually exclusive.

The headline was disambiguated only on page 17 of the newspaper, where the cover headline was explained indicating that Kato's friends are worried that the policemen are desperately looking for a way to put Kato behind bars for perjury. The problem with the cover headline is what an average reader could think in the context of the O.J. Simpson's trial for murder in which Kato was involved. The defendants interpreted the utterance within the co-text of the publication, showing that it was later explained in the article. However, the court took into account the broadest communicative context in which the headline appeared, i.e., among the headlines of other journals, since the front page of the tabloid paper is what the paper is 
sold on, not what's inside it. For this reason, a reasonable reader is presumed to interpret the headline as referring to the murders, and for this reason the statement was considered as defamatory.

\subsection{Illocutionary Pragmatic Ambiguity}

The second type of pragmatic ambiguity that can be exploited for the purposes of misquotation is illocutionary ambiguity. According to the rule set out in Masson, in order to establish falsity it is necessary to determine whether there is "difference in effect on the mind of the reader from that which the pleaded truth would have produced" (501 U.S. at 516-17). The problem with reporting intentions is that literal meaning is subject to different interpretations, depending on the intention of the speaker in a specific dialogical setting. In order to establish the individual intention, it is necessary to look at the dialogical context and the joint communicative purpose. By distorting, omitting, or misrepresenting the latter, it is possible to misquote a statement without altering its literal meaning, but only its illocutionary effect. This strategy can be used for both the purpose of pressing a charge of defamation and rejecting it.

As mentioned above, in order to interpret a quote it is necessary to consider not only the words used, but the communicative intention of the speaker, which can be drawn from the co-text and the context of dialogue. For attacking purposes, a quote can be taken out of its dialogical setting, so that a prima-facie defamatory statement is assessed without considering the possible intention with which it has been uttered. A clear example of the relationship between interpretation and dialogical intentions is MacElree v. Philadelphia Newspaper, Inc.. Further to an altercation at Lincoln University, Philadelphia Newspaper, Inc. published an article in which a quote by the university attorney was reported, calling MacElree (then the Chester County District Attorney) "the David Duke of Chester County" (437 Pa. Super. 598, at 601 1994):

Case 8: Interpretation of metaphors

Writing to a local newspaper, [University President Siara] Sudarkasa questioned remarks by the Chester County district attorney that one of the New Yorkers had been stabbed. When D.A. James MacElree replied with quotations from police reports, the university's lawyer, Richard Glanton, accused him of electioneering - "the David Duke of Chester County running for office by attacking Lincoln."

According to the plaintiff, the comparison was a statement of fact, which was explained (or rather reported) as follows: Glanton stated that MacElree was "a white supremacist, white separatist, racist zealot with neo-Nazi beliefs and practices." The plaintiff reported the statement explicating its meaning including the possible inferences that could be drawn from it. However, the court reasoned taking into account the context of dialogue reported by the newspaper, and the ambiguity of a metaphor (Macagno and Zavatta 2014). The Court noted that the plaintiff 
took the quote out of the context of the article, in which the dialogical context (a quarrel between MacElree and Glanton) was clearly reported. In such a context, a heated discussion, the purpose of the speaker was merely to "give vent to insult" (see also Greenbelt Pub. Assn. v. Bresler, 398 U.S. 6, 1970). For this reason, the statement could be interpreted by an average reader as merely reporting an opinion ("Glanton name-called MacElree, comparing him with David Duke"). According to the provisions of law governing the analysis of the context of alleged defamatory statements (Restatement (Second) of Torts, § 566 comment e.), "a certain amount of vulgar name-calling is frequently resorted to by angry people without any real intent to make a defamatory assertion." The utterance, taken in its dialogical context, was interpreted and explained as amounting to an attack in a quarrel, bearing no defamatory intentions.

The interpretation of an utterance taken out of its dialogical context can be used as a powerful defensive strategy. In the leading famous case Milkovich v. Lorain Journal Co. (497 U.S. 1, 1990), the defendants managed to show that a primafacie defamatory statement was in fact a mere opinion by selecting what counted as the relevant context. The case concerned a testimony given by the coach of the wrestling team Maple Heights, Mr. Milkovich, further to an altercation ended up in court. A columnist of the Lorain Journal Co. commented on the testimony in an article entitled "Maple beat the law with the big lie," using the following words (497 U.S. 1, at 5):

Case 9: Interpretation of the pragmatic purpose: fact or opinion

Anyone who attended the meet, whether he be from Maple Heights, Mentor, or impartial observer, knows in his heart that Milkovich and Scott lied at the hearing after each having given his solemn oath to tell the truth. [...] But they got away with it. [...] Is that the kind of lesson we want our young people learning from their high school administrators and coaches? I think not.

Milkovich accused the journal of defamation, as the journal reported an alleged false fact. The defendants rejected the accusation using a twofold strategy. On the one hand, they interpreted the disputed statement, "Anyone who attended the meet, [...] knows in his heart that Milkovich and Scott lied at the hearing" as indirectly reporting an opinion of the attendants, which could not be verified. On the other hand, they interpreted the statement within its broader context. Since "the article appeared on a sports page, a traditional haven for cajoling, invective, and hyperbole, the article would probably be construed as opinion." (497 U.S. 1, at 10).

However, the Supreme Court rejected both claims. Since the newspaper reported a verifiable fact, the statement needs to be considered as factual, and in this specific case as false. Moreover, the Court noticed that the "broader context" was limited to the type of publication, and did not take into account the actual context and co-text, namely the whole tenor of the article, and the presumptive interpretation that it could trigger. The Supreme Court analyzed the statement as a part of a communication to an average reader, and calculated the possible conclusions that can be drawn from it. Since the article never negated or tried to negate the impression that the writer 
held facts supporting the opinion that Milkovich lied, the reporter's statement needs to be read as a false statement of fact (497 U.S. 1, at 19).

\subsection{Perlocutionary Ambiguity}

The problem of establishing the meaning of a speech act and its illocutionary force (to express a description of a state of affairs or to attack or praise the interlocutor) needs to be distinguished from a subtler issue, the intended perlocutionary effects that a statement can have on the audience. A statement of fact can be used for different purposes, i.e., to elicit directly different reactions. According to the law, a quote needs to be interpreted according to its intended effects, encompassing the perlocutionary effects that a statement is directly intended to produce on the hearer (believing in what the statement says; despising the individual attacked, etc.). A quote is regarded as false not only when its propositional content or its illocutionary force is altered, but also when the speaker has intended his assertion to produce an effect different from the one that has been wrongfully attributed to it.

A famous case of manipulation of the perlocutionary effects of an assertion is the lawsuit Sherrod v. Breitbart (case no. 000157 11, District of Columbia 2011). The complaint stems from a March 2010 speech that Ms. Sherrod, an African American former Georgia state director of rural development for the United States Department of Agriculture, gave to the NAACP (National Association for the Advancement of Colored People), and the defendants' subsequent treatment of that speech. Breitbart posted an edited video of Sherrod's speech along with slides alleging that Sherrod carried out her USDA duties "through the prism of race and class distinctions," pointing out that her words elicited racial reactions in the audience. After the publication of the video, Sherrod was asked to leave her job because of the racist claims and ensuing media uproar. The excerpted video contained the following language (emphasis added) ${ }^{1}$ :

Case 10: Interpretation of the perlocutionary purpose

The first time I was faced with having to help a white farmer save his farm, $[\ldots]$ he was taking all that time trying to show me he was superior to me, was I was trying to decide just how much help I was going to give him. [audience chuckled] I was struggling with the fact that so many black people have lost their farmland, and here I was faced with having to help a white person save their land. So, I didn't give him the full force of what I could do. I did enough so that when he - I - I assumed the Department of Agriculture had sent him to me, either that or the - or the Georgia Department of Agriculture. And he needed to go back and report that I did try to help him. [ . . ] So I figured if I take him to one of them that his own kind would take care of him. That's when it was revealed to me that, ya'll, it's about poor versus those who have, and not so much about white - it is about white and black, but it's not - you know, it opened my eyes, 'cause I took him to one of his own...

\footnotetext{
${ }^{1}$ http://factreal.wordpress.com/2010/07/22/full-transcript-videos-usda-shirley-sherrod-naacpbreitbart-foxnews/. Last accessed on 17 Aug 2014.
} 
The video was posted on a website addressing the debate on racial discrimination within the Tea Party and the NAACP. In this context, considering Breitbart's comments and his insinuation that the speech was received with applause by the audience, the excerpt sounded as clearly intended to convey a racial message, a personal story of discrimination. However, the post omitted the whole co-text and, more importantly, the intended effect that Sherrod wanted to elicit. Sherrod's purpose was to tell the audience how she changed her commitment to help black people, and decided to commit instead to the struggle against poverty. Her story was one of redemption from old resentments for the racial discriminations that she and her family suffered from since she was a kid. In addition to making clear later in the video that she helped the farmer as much as she could, she introduced her narration with the following words, describing her internal struggle when she was appointed as State Director of Rural Development:

Case 11: Dialogical context

But when I . . . made the commitment years ago I didn't know how — I didn't ... I prayed about it that night and as our house filled with people I was back in one of the bedrooms praying and asking God to show me what I could do. I didn't have - the path wasn't laid out that night. $[\ldots]$. And young people I just want you to know that when you're true to what God wants you to do the path just opens up - and things just come to you, you know. God is good - I can tell you that. When I made that commitment, I was making that commitment to black people - and to black people only. But, you know God will show you things and He'll put things in your path so that - that you realize that the struggle is really about poor people, you know.

The intended perlocutionary effect was to tell to the audience an almost religious experience on discrimination and poverty, and show them where the real problem was. ${ }^{2}$ However, by wrenching the quote from its original context, Breitbart turned this intended purpose into a racist story.

\section{Presumptive and Systematic Reasoning in Reporting Intentions}

The rules used at common law in the United States for interpreting, explicating, and reporting quotations bring to light the essential relationship between the pragmatic purpose of an utterance and its meaning. The pragmatic goal, in particular, is reconstructed through the co-text and the context, which can reveal the speaker's communicative intentions. The complexity of the process of retrieving communicative intentions emerges from the strategies of reporting intentions, which are used by newspapers for proving a specific point, or, in a court of law, for defensive or attacking purposes. In particular, the most problematic and controversial cases are represented by pragmatic ambiguity, in which a different intention is attributed to

\footnotetext{
${ }^{2}$ As a matter of fact, the intended effect was clearly perceived by the audience, http://www.slate. com/articles/news_and_politics/frame_game/2010/07/amen_canard.html
} 
the speaker by wrenching his statement from its dialogical context. This strategy for introducing ambiguity becomes relevant for the fields of pragmatics and argumentation theory, as it is strictly connected with the problem of representing intentions. In particular, the creation of ambiguity at a pragmatic level is grounded on a conflict between the presumptive interpretation of a speech act, and the nonheuristic one resulting from the analysis of its dialogical function (Macagno 2012; Macagno and Walton 2013). The process of interpretation of a speech act, or rather the explicative passage from a quote to an indirect report, needs to be described by accounting for the conflict between the presumptive and the systematic reasoning underlying meaning reconstruction. To this purpose, it can be useful to combine the studies in pragmatics with the insights from argumentation theory.

\subsection{Indirectly Reporting: Individual Intentions}

In argumentation theory, a speech act is regarded as a specific verbal act within an interaction, which can be a discourse or a dialogue. For this reason, it can be also referred to as a discourse unit when it is part of an act complex (Van Eemeren and Grootendorst 1984: 34) or a dialogue move when part of a dialogue. On this perspective, communicative intentions are modeled as argumentative relations between speech acts and their conversational setting. A discourse move cannot be a "disconnected remark" (Grice 1975: 45) but rather an effort to reach a common dialogical purpose. For this reason, every speech act needs to be conceived as a move grounded on previous conditions (the co-text and the context), and aimed at achieving a specific dialogical purpose, i.e., a specific dialogical effect onto the interlocutor. Such effects can be defined both in dialectical terms as the limitation of the paradigm of an interlocutor's possible replies (Ducrot 1972; Macagno and Walton 2014, Ch. 7), and in dialogical terms as the intended, minimal and optimal, perlocutionary effects onto the hearer (Raudenbush 1991: 1463-1465).

This twofold relationship between a speech act, its co-text and context, and the further moves that it allows and leads to can be represented as an abstract pragmatic predicate called "rhetorical predicate" (Grimes 1975: 209), "coherence relation" (Hobbs 1979: 68; Hobbs 1985), or connective predicate (Crothers 1979; Rigotti 2005). Connective predicates can be conceived as a representation of the speaker's communicative intention, as it can be reconstructed from a text. Inasmuch as a predicate, it imposes a set of coherence conditions (or pragmatic presuppositions, see Vanderveken 2002: 47; Bach 2003: 163; Kempson 1973) on its arguments, i.e., the previous and the subsequent dialogue moves.

The idea of analyzing a speech act in its dialogical context allows one to reconstruct its permissible inferences and evaluate its interpretation, or its indirect report. For instance let us consider the following explicature of the aforementioned case 3 above:

I. Masson said: "I was a private asset but a public liability." 
This quote was interpreted (reported) as follows:

I'. (A) Masson said that he was an intellectual gigolo.

The problem that this interpretation arises is that it can be justified (as it was) based on the possibility of drawing from it a non-defamatory inference:

I". <Therefore, (B) his views were privately entertaining, but publicly embarrassing.>

This relationship between the two moves (A and the implicit one, B) consists in an argument from classification based on a classificatory principle (Walton, Reed and Macagno 2008; Walton and Macagno 2009, Macagno and Walton 2014) aimed at supporting a value judgment on the subject. An "intellectual gigolo" is commonly defined as a person who forsakes intellectual integrity in exchange for pecuniary or other gain. For this reason, the most common and direct evaluative inference would support a judgment on the dishonesty of the subject's intellectual behavior (which we can refer to as B'), rather than one on the social acceptability of his views. However, given the implicit nature of the conclusion, the reconstruction of the connective predicate becomes more complex. In this case, it is necessary to reconstruct the whole context (indicated as $\mathrm{A}^{-1}$ ) and analyze and assess the possible alternatives, excluding the less reasonable ones:

I"'. ( $\left.\mathrm{A}^{-1}\right)$ Masson said that they loved to hear from him what creeps and dolts analysts are. (A) Masson said that he was an intellectual gigolo. $<$ Therefore, (B) his views were privately entertaining, but publicly embarrassing.>

In this case, $\mathrm{A}^{-1}$ specifies the meaning of the classification mentioned in $\mathrm{A}$, pointing out that Masson was classified as an intellectual gigolo from a professional point of view. The epithet needs to be taken literally, as he revealed in breach of the professional code of conduct details concerning his colleagues that were entertaining, but harmful to their reputation. In this sense, the conclusion B that is drawn from the previous moves is unsupported by the meaning of "intellectual gigolo" that can be reconstructed from the context and that is commonly shared. While the features of being "entertaining" and "embarrassing" constitute respectively a feature of the concept of "gigolo" and a possible inference that can be drawn from it, the fundamental characteristic of "forsaking integrity for gain" (pointed out in $\mathrm{A}^{-1}$ and preserved in B') is lost. For this reason, in comparing B with B's for the purpose of assessing the implicit communicative intention of $\mathrm{A}, \mathrm{B}$ needs to be considered as less supported by the co-textual and contextual information than B'.

\subsection{Indirectly Reporting: Joint Intentions}

The idea of modeling relevance relations as argumentative links between the various moves allows one to analyze the felicity of a possible continuation of a dialogue or conclusion that can be drawn from a speech act in terms of argumentative 
reasonableness (Macagno and Damele 2013; Walton et al. 2008). However, the idea of representing intentions as predicates leads to the problem of representing joint intentions, i.e., the shared purpose in an interaction. Connective predicates represent the individual dialogical goal in a communicative exchange (Rocci 2005: 103). However, any individual intention in communication is formed within an interaction with interlocutors or an audience, i.e., a joint activity in which different individual goals need to adapt to and be coherent with a joint purpose (Rocci 2005: 104-106). This joint purpose can be imagined as a higher connective predicate, a dialogue-game predicates (Rocci 2005: 106; Walton and Macagno 2007) connecting the speech acts of a dialogue, and the individual communicative goals, with the purpose of a joint collaborative verbal activity (Grice 1975: 45; van Eemeren and Grootendorst 2004: 72). In this sense, the abstract higher predicate imposes his conditions on each speech act (Grosz and Sidnert 1986: 178; Walton 1989: 68). The text is thus thought of as a hierarchy of predicates connecting discourse units.

As every speech act has to provide a contribution to the achievement of a common goal, it must comply with specific requirements, namely the quality and the quantity of the provided contribution, its relation with what has been said before and the conversation goal, as well as the manner in which it is issued. The listener expects the received contribution to be meaningful and compliant with the dialogue game predicate, and triggers an interpretative reasoning aimed at retrieving the speaker's intention. If the presumptive meaning does not respect the requirements of the predicate, the listener begins to look for an alternative interpretation of speaker's intention (Macagno and Walton 2013, 2014).

Depending on the type of dialogue game, the dialogue-game predicate will impose different conditions on its arguments, which will guide also the process of interpretation. For example, we consider the following statement, uttered in the context of a heated discussion (Greenbelt Pub. Assn. v. Bresler, 398 U.S. 6, 1970):

II. Mr. Bresler is blackmailing the city council of Greenbelt.

The speaker uttered such words that were later indirectly reported by a local newspaper as follows (at 7):

II'. Various citizens had characterized respondent's negotiating position as "blackmail."

Mr. Bresler pressed charges for defamation, indirectly reporting the newspaper indirect quotation and explicating it as follows (at 7):

II". The newspaper published a false statement claiming that I have committed the crime of blackmail.

Bresler interpreted the citizens' statement (and the newspaper's indirect report) as an accusation of a crime, aimed at informing the audience of his alleged extortion by threat. Bresler disregarded the context in which the statement was made, which was carefully reported by the newspaper, that is, a heated discussion that can be represented as a quarrel, aimed at giving vent to insults and emotions. In such a dialogical condition, the statement needs to be read as having a purpose (insulting, 


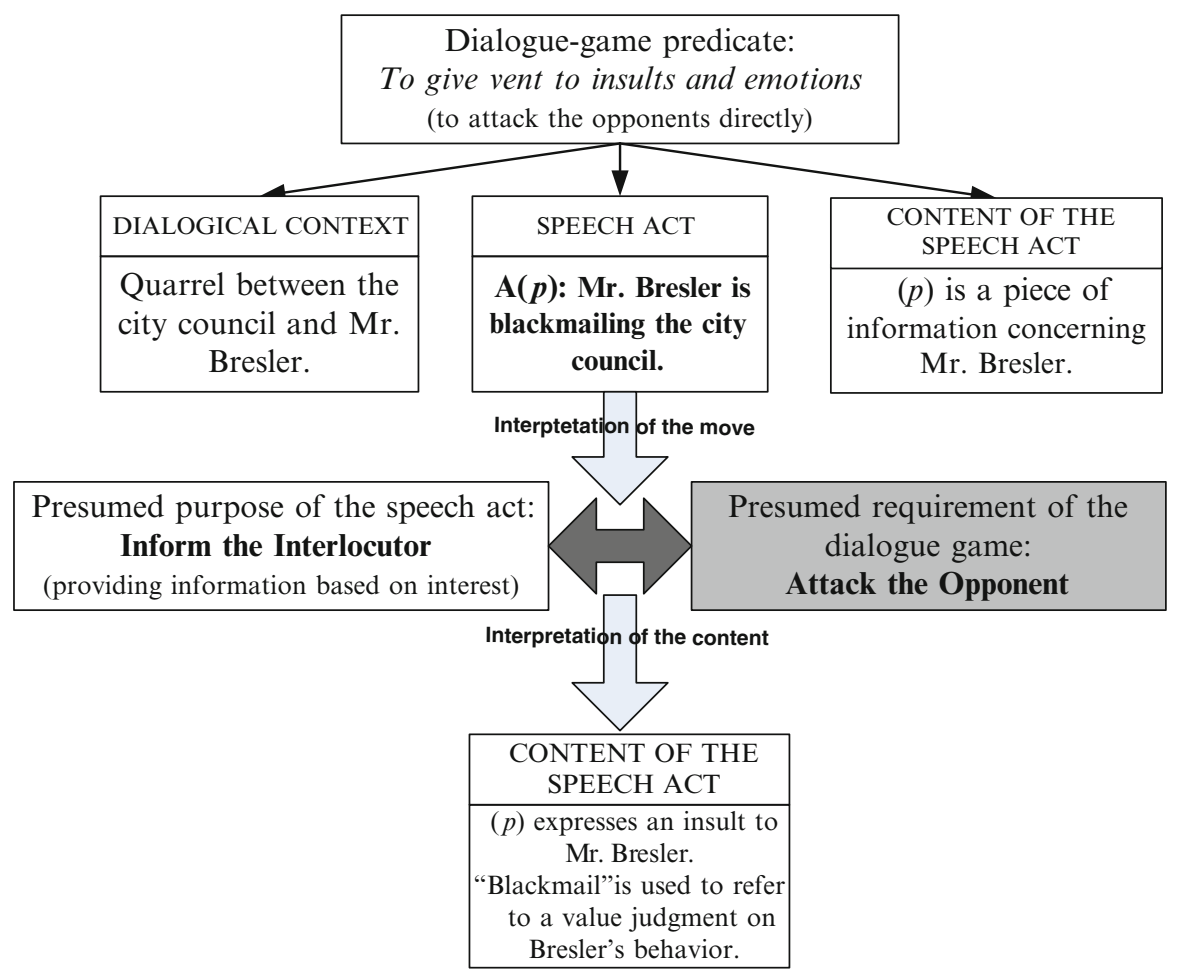

Fig. 2 Dialogue-game predicate and connective predicate

namely expressing a negative opinion on Mr. Bresler) different from the one that would be commonly attributed to it in a dialogue aimed at exchanging information. The relationship between the dialogue game predicate and the interpretation of the individual communicative intention can be diagrammed as in Fig. 2.

The presumptive interpretation of the speech act, i.e., to inform the interlocutor, needs to be analyzed in consideration of the dialogue-game predicate. In this case, the joint dialogical intention can be considered as engaging in a quarrel, and for this reason the individual moves are presumed to attack the interlocutor. This non-presumptive communicative intention will guide the interpretation of the propositional content of the move. In this case, the term "to blackmail" is interpreted metaphorically as a mere value judgment on Bresler's behavior (Macagno and Zavatta 2014):

II"'. The city council of Greenbelt said that Mr. Bresler was (behaving extremely aggressively during the negotiations).

The joint dialogical purpose is a principle for establishing also the intended inherent (or minimal) and consecutive (or optimal) perlocutionary effects of a move (Van Eemeren and Grootendorst 1984: 69; Trosborg 1995: 22-23). For example, 
an assertion of a viewpoint can be aimed at placing the interlocutor in a situation where he can accept or reject the advanced position (inherent effect), and optimally at leading him to the acceptance thereof. In a specific dialogical setting, a speaker can aim to elicit a dialogical reaction such as to arouse pity, or indignation (Asher and Lascarides 2003). This dialogical goal can be used to reconstruct the inherent effect of each speech act. For example, depending on the dialogical goal of the discourse, the following assertion (case 10 above) can be interpreted as having distinct perlocutionary purposes:

III. The first time I was faced with having to help a white farmer save his farm, [... ] I didn't give him the full force of what I could do.

This statement can be presumptively interpreted as statement aimed at informing the public about the speaker's past racial behavior:

III'. <Ms. Sherrod informed the audience of how she took revenge against white people, saying $>$ the first time she was faced with having to help a white farmer save his farm, $[\ldots]$ she didn't give him the full force of what she could do.

However, in a context in which the speaker is talking about an almost religious discovery about the meaning of her work, the narration becomes a story of redemption aimed at teaching the audience a meaningful experience:

III". <Ms. Sherrod told the audience how she understood her mission, saying that> the first time she was faced with having to help a white farmer save his farm, $[\ldots]$ she didn't give him the full force of what she could do $<$ which revealed her that the problem was poverty and not race $>$.

Instead of arousing racial feelings, the assertion inherently wanted to elicit indignation against racism in general, and teach the audience a lesson on the struggle against poverty to be fought.

\section{Conclusion}

The interpretation of a speaker's communicative intentions is a crucial problem in law, where it traces the crucial boundary between defamation and correct reporting, and between relating one owns' claims or the opponent's ones and distorting the parties' commitments. The effectiveness of the strategies of misreporting depends on two dimensions. On the one hand, they need to have a communicative effect, which can be rhetorical or dialectical. A speaker's words can be misinterpreted or misreported to attack his character and arouse attention or criticize him. The claims of an opponent in a discussion can be reported incorrectly, so that it becomes easier to defeat his standpoint. A party to a dialogue can also distort a quote of his own, in order to disprove the interlocutor's accusations. On the other hand, such distortions need to be dialectically efficient. A misquotation or an incorrect report 
has the dialectical effect of attributing to the speaker commitments that he never held, which the latter needs to reject by providing arguments. This shifting of the burden of persuasion can be increased by using strategically the conflict between the presumptive interpretation of an utterance and its actual communicative intention that can be retrieved through its dialogical context.

Effective strategies of misreporting are based on pragmatic ambiguity at different levels. By wrenching an utterance from its context, it is possible to lead the interlocutor or the audience to reconstructing its contextual logical form by retrieving the most accessible referents of the indexical expressions. This presumptive reconstruction is not stated, but simply suggested. Illocutionary ambiguity is exploited to turn personal opinions, value judgments, and attacks into statements of fact, which can fall under the provisions of defamation law. By omitting the dialogical context, an utterance can be interpreted presumptively as aimed at representing a state of affairs, and not at giving vent to emotions or personal judgments. Similarly, the same choice of wrenching a quote from its context can be used to misrepresent the perlocutionary inherent effects of an utterance, which can lead the process of interpretation. These three strategies are not on the same level. In particular, perlocutionary and illocutionary ambiguity can affect the interpretation of the propositional form of an utterance, especially when a term can be interpreted either literally or metaphorically.

The passage from a statement to its interpretation, or indirect report, is based on the strict relationship between dialogical intentions and the reconstruction of meaning at different levels, which can be represented through a hierarchy of predicates, dominated by the dialogical intention. The joint communicative goal can be determined by the type of dialogue (Walton 1998: 30; Walton and Krabbe 1995: 66) the interlocutors are engaged in. This higher predicate imposes the relevance conditions onto the various speech acts, which need to be interpreted according to their compliance with the requirements of the dialogical goal (Walton and Macagno 2007). The individual intention governing an utterance can be thus retrieved, and its felicity conditions can be reconstructed. This process can guide the interpretation of the propositional content, leading to a non-presumptive interpretation of meaning (Macagno 2012; Macagno and Zavatta 2014).

When an interpreter is confronted with an utterance taken out of its dialogical context, his interpretative process cannot rely on a systematic analysis of the actual dialogical predicate, which is thus reconstructed presumptively, according to the most frequent or prototypical dialogical setting in which the utterance could have occurred, or the most typical individual purpose that it could have served to achieve. This presumptive reconstruction can be carried out at all levels, and can be used to provide a prima-facie case that the other party needs to reject. The stronger the interpretative presumptions a speaker needs to rebut, the more effective the misrepresentation strategy. 


\section{References}

Asher, N., \& Lascarides, A. (2003). Logics of conversation. Studies in natural language processing. Cambridge: Cambridge University Press.

Bach, K. (2003). Speech acts and pragmatics. In M. Devitt \& R. Hanley (Eds.), Blackwell. Guide to the philosophy of language (pp. 147-167). Oxford: Blackwell.

Bezuidenhout, A. (1997). Pragmatics, semantic under determination and the referential/attributive distinction. Mind, 106(423), 375-407.

Blair Edlow, R. (1977). Galen on language and ambiguity. Leiden: E.J. Brill.

Boller, P. (1967). Quotemanship. Dallas: Southern Methodist University Press.

Burton-Roberts, N. (2006). Cancellation and intention. Newcastle Working Papers in Linguistics, $12-13,1-12$.

Capone, A. (2003). Theories of presuppositions and presuppositional clitics. In P. Kühnlein, H. Rieser, \& H. Zeevat (Eds.), Perspectives on dialogue in the new millennium (pp. 111-133). Amsterdam: John Benjamins.

Capone, A. (2009). Are explicatures cancellable? Toward a theory of the speaker's intentionality. Intercultural Pragmatics, 6(1), 55-83.

Capone, A. (2010). On the social practice of indirect reports (further advances in the theory of pragmemes). Journal of Pragmatics, 42, 377-391.

Capone, A. (2011). The attributive/referential distinction, pragmatics, modularity of mind and modularization. Australian Journal of Linguistics, 31(2), 153-186.

Capone, A. (2013). The pragmatics of indirect reports and slurring. In A. Capone et al. (Eds.), Perspectives on linguistic pragmatics. Perspectives in pragmatics, philosophy and psychology 2 (pp. 153-183). Berlin: Springer.

Carston, R. (1997). Enrichment and loosening: Complementary processes in deriving the proposition expressed? In E. Rolf (Ed.), Pragmatik (pp. 103-127). Wiesbaden: Springer.

Carston, R. (2002). Thoughts and utterances. The pragmatics of explicit communication. Oxford: Blackwell.

Copi, I., \& Cohen, C. (1990). Introduction to logic (8th ed.). New York: Macmillan.

Crothers, E. (1979). Paragraph structure inference. Norwood: Ablex.

De Grazia, M. (1995). Sanctioning voice: Quotation marks, the abolition of torture, and the fifth amendment. In M. Woodmansee \& P. Jaszi (Eds.), The construction of authorship: Textual appropriation in law and literature (pp. 281-302). Durham \& London: Duke University Press.

Ducrot, O. (1972). Dire et ne pas dire. Paris: Hermann.

Ducrot, O., \& Anscombre, J. C. (1986). Argumentativité et informativité. In M. Michel (Ed.), De la métaphysique à la rhétorique (pp. 79-93). Bruxelles: Éditions de l'Université de Bruxelles.

Engel, M. (1980). Analyzing informal fallacies. Englewood Cliffs: Prentice-Hall.

Grice, P. (1975). Logic and conversation. In D. Davidson \& G. Harman (Eds.), The logic of grammar (pp. 64-75). Encino: Dickenson.

Grimes, J. (1975). The thread of discourse. The Hague: Mouton.

Grosz, B., \& Sidnert, C. (1986). Attention, intentions, and the structure of discourse. Computational. Linguistics, 12(3), 175-204.

Hobbs, J. (1979). Coherence and coreference. Cognitive Science, 3, 67-90.

Hobbs, J. (1985). On the coherence and structure of discourse. Report No. CSLI-85-37. Center for the Study of Language and Information, Stanford University.

Jaszczolt, K. (1999). Discourse, beliefs and intentions. Oxford: Elsevier.

Kaltenbach, R. (1992). Fabricated quotes and the actual malice standard: Masson v. New Yorker magazine. Catholic University Law Review, 41, 745-777.

Kempson, R. (1973). Presupposition: A problem for linguistic theory. Transactions of the Philological Society, 72(1), 29-54.

Lascarides, A., \& Asher, N. (1991). Discourse relations and defeasible knowledge. In Proceedings to the 29th annual meeting of the association of computational linguistics (ACL91), Berkeley USA (pp. 55-63). Stroudsburg: Association for Computational Linguistics. 
Macagno, F. (2008). Dialectical relevance and dialogical context in Walton's pragmatic theory. Informal Logic, 28(2), 102-128.

Macagno, F. (2012). Presumptive reasoning in interpretation. Implicatures and conflicts of presumptions. Argumentation, 26(2), 233-265.

Macagno, F., \& Damele, G. (2013). The dialogical force of implicit premises: Presumptions in enthymemes. Informal Logic, 33(3), 365-393.

Macagno, F., \& Walton, D. (2013). Implicatures as forms of argument. In A. Capone et al. (Eds.), Perspectives on pragmatics and philosophy (pp. 203-224). Berlin/New York: Springer.

Macagno, F., \& Walton, D. (2014). Emotive language in argumentation. New York: Cambridge University Press.

Macagno, F., \& Zavatta, B. (2014). Reconstructing metaphorical meaning. Argumentation, 28(4), 453-488.

Oswald, S., \& Lewinski, M. (2013). When and how do we deal with straw men? A normative and cognitive pragmatic account. Journal of Pragmatics, 59, 164-177.

Paglieri, F. (2007). No more charity, please! Enthymematic parsimony and the pitfall of benevolence. In C. Tindale \& H. Hansen (Eds.), Dissensus and the search for common ground. OSSA proceedings (pp. 1-26). Windsor: University of Windsor.

Raudenbush, E. (1991). Variations on a theme: Application of Masson v. New Yorker Magazine, Inc. to a spectrum of misquotation libel cases. Washington \& Lee Law Review, 48, 1441-1475.

Recanati, F. (2004). 'What is said' and the semantics/pragmatics distinction. In C. Bianchi (Ed.), The semantics/pragmatics distinction (pp. 45-64). Stanford: CSLI Publications, Stanford University.

Rescher, N. (1977). Dialectics: A controversy-oriented approach to the theory of knowledge. Albany: State University of New York Press.

Rigotti, E. (2005). Congruity theory and argumentation. Studies in Communication Sciences, (Special Issue), 75-96.

Rocci, A. (2005). Connective predicates in monologic and dialogic argumentation. Studies in Communication Sciences, (Special Issue), 97-118.

Siegel, P. (2014). Communication law in America. Lanham: Rowman \& Littlefield.

Soames, S. (2002). Beyond rigidity: The unfinished semantic agenda of naming and necessity. New York: Oxford University Press.

Solan, L., \& Tiersma, P. (2005). Speaking of crime. The language of criminal justice. Chicago/London: The University of Chicago Press.

Sperber, D., \& Wilson, D. (1986). Relevance. Oxford: Blackwell.

Stevenson, C. L. (1937). The emotive meaning of ethical terms. Mind, 46, 14-31.

Stevenson, C. L. (1944). Ethics and language. New Haven, CT: Yale University Press.

Trosborg, A. (1995). Interlanguage pragmatics: Requests, complaints, and apologies. The Hague: Mouton de Gruyter.

Van Eemeren, F., \& Grootendorst, R. (1984). Speech acts in argumentative discussions: A theoretical model for the analysis of discussions directed towards solving conflicts of opinion. Dordrecht: Foris.

van Eemeren, F., \& Grootendorst, R. (2004). A systematic theory of argumentation: The pragmadialectical approach. Cambridge: Cambridge University Press.

Van Laar, J. A. (2003). The dialectic of ambiguity: A contribution to the study of argumentation. Ph.D. dissertation. Groningen: University of Groningen.

Vanderveken, D. (2002). Universal grammar and speech act theory. In D. Vanderveken \& S. Kubo (Eds.), Essays in speech act theory (pp. 25-62). Amsterdam: John Benjamins.

Walton, D. (1989). Informal logic. New York: Cambridge University Press.

Walton, D. (1996). Fallacies arising from ambiguity. Dordrecht: Kluwer.

Walton, D. (1998). The new dialectic. Conversational contexts of argument. Toronto: University of Toronto Press.

Walton, D. (2000). New dialectical rules for ambiguity. Informal Logic, 20(3), 261-274.

Walton, D. (2006). Fundamentals of critical argumentation. New York: Cambridge University Press. 
Walton, D., \& Krabbe, E. (1995). Commitment in dialogue. Albany: State University of New York Press.

Walton, D., \& Macagno, F. (2007). Types of dialogue, dialectical relevance, and textual congruity. Anthropology \& Philosophy, 8(1-2), 101-121.

Walton, D., \& Macagno, F. (2009). Reasoning from classification and definition. Argumentation, 23, 81-107.

Walton, D., \& Macagno, F. (2010). Wrenching from context: The manipulation of commitments. Argumentation, 24(3), 283-317.

Walton, D., \& Macagno, F. (2011). Quotations and presumptions - Dialogical effects of misquotations. Informal Logic, 31(1), 27-55.

Walton, D., Reed, C., \& Macagno, F. (2008). Argumentation schemes. New York: Cambridge University Press.

Wieland, N. (2013). Indirect reports and pragmatics. In A. Capone, F. Piparoand, \& M. Carapezza (Eds.), Perspectives on pragmatics and philosophy (pp. 389-411). Dordrecht: Springer. 